\title{
Medication Related Osteonecrosis of the Jaw: 2021 Position Statement of the Korean Society for Bone and Mineral Research and the Korean Association of Oral and Maxillofacial Surgeons
}

\author{
Jin-Woo Kim,*, Mi Kyung Kwak ${ }^{2, *}$, Jeong Joon Han³, Sung-Tak Lee ${ }^{4}$, Ha Young Kim ${ }^{5}$, Se Hwa Kim 6 , Junho Jung ${ }^{7}$, \\ Jeong Keun Lee ${ }^{8}$, Young-Kyun Lee ${ }^{9}$, Yong-Dae Kwon ${ }^{7, \dagger}$, Deog-Yoon Kim ${ }^{10,+}$ \\ 'Department of Oral and Maxillofacial Surgery, School of Medicine, Ewha Womans University, Seoul; \\ ${ }^{2}$ Division of Endocrinology and Metabolism, Department of Internal Medicine, Hallym University Dongtan Sacred Heart Hospital, Hwaseong; \\ ${ }^{3}$ Department of Oral and Maxillofacial Surgery, School of Dentistry, Dental Research Institute, Seoul National University, Seoul; \\ ${ }^{4}$ Department of Oral and Maxillofacial Surgery, School of Dentistry, Kyungpook National University, Daegu; \\ ${ }^{5}$ Division of Endocrinology and Metabolism, Department of Internal Medicine, Gangneung Asan Hospital, University of Ulsan College of \\ Medicine, Gangneung; \\ ${ }^{6}$ Division of Endocrinology and Metabolism, Department of Internal Medicine, International St. Mary's Hospital, Catholic Kwandong \\ University College of Medicine, Incheon; \\ ${ }^{7}$ Department of Oral and Maxillofacial Surgery, School of Dentistry, Kyung Hee University, Seoul; \\ ${ }^{8}$ Department of Oral and Maxillofacial Surgery, Institute of Oral Health Science, Ajou University Dental Hospital, Ajou University School of \\ Medicine, Suwon; \\ ${ }^{9}$ Department of Orthopaedic Surgery, Seoul National University Bundang Hospital, Seoul National University College of Medicine, Seongnam; \\ ${ }^{10}$ Department of Nuclear Medicine, Kyung Hee University Hospital, Kyung Hee University School of Medicine, Seoul, Korea
}

\section{Corresponding authors}

Yong-Dae Kwon

Department of Oral and Maxillofacial Surgery, School

of Dentistry, Kyung Hee University, 23 Kyungheedae-ro,

Dongdaemun-gu, Seoul 02447, Korea

Tel: +82-2-958-9440, Fax: +82-2-966-4572

E-mail: yongdae.kwon@gmail.com; kwony@khu.ac.kr

Deog-Yoon Kim

Department of Nuclear Medicine, Kyung Hee University Hospital, Kyung Hee University School of Medicine, 23

Kyungheedae-ro, Dongdaemun-gu, Seoul 02447, Korea

Tel: +82-2-958-8211, Fax: +82-2-968-1848

E-mail: deogyoon@daum.net

Received: October 22, 2021

Revised: November 9, 2021

Accepted: November 15, 202

* Jin-Woo Kim and Mi Kyung Kwak contributed equally to this work and should be considered co-first authors.

†Yong-Dae Kwon and Deog-Yoon Kim contributed equally to this work and should be considered co-corresponding authors.

Copyright $@ 2021$ The Korean Society for Bone and Mineral Research

This is an Open Access article distributed under the terms of the Creative Commons Attribution Non-Commercial License (https://creativecommons.org/licenses/by-nc/4.0/) which permits unrestricted non-commercial use, distribution, and reproduction in any medium, provided the original work is properly cited.
Antiresorptives are the most widely prescribed drugs for the treatment of osteoporosis. They are also used in malignant bone metastases, multiple myeloma, and Paget's disease, and provide therapeutic efficacy on those diseases. However, it was reported that the occurrence of osteonecrosis of the jaw (ONJ) could be related to antiresorptive exposures, and there have been many cases regarding this issue. Therefore, a clearer definition and treatment guidelines were needed for this disease. The American Society for Bone and Mineral Research and the Amnerican Association of Oral and Maxillofacial Surgeons reported statements on bisphosphonate-related ONJ (BRONJ), and a revised version was recently presented. In the revised edition, the diagnosis BRONJ was changed to medication-related ONJ (MRONJ), which reflects consideration of the fact that ONJ also occurs for denosumab, a bone resorption inhibitor of the receptor activator of the nuclear factor-KB ligand antibody family, and bevacizumab, an anti-angiogenesis inhibitor. The Korean Society for Bone and Mineral Research and the Korean Association of Oral and Maxillofacial Surgeons had collectively formed a task force for the preparation of an official statement on MRONJ based on a previous position paper in 2015. The task force reviewed current knowledge and coordinated dental and medical opinions to propose the guideline customized for the local Korean situation.

Key Words: Bisphosphonate-associated osteonecrosis of the jaw - Bone density conservation agents · Osteoporosis 


\section{BACKGROUND}

Medication-related osteonecrosis of the jaw (MRONJ) adversely affects the quality of life and leads to significant morbidity. Since the first report of pamidronate and zoledronate induced ONJ by Marx [1] in 2003, there have been numerous reports supporting causality of bisphosphonates (BPs) and the disease. In 2014, American Association of Oral and Maxillofacial Surgeons (AAOMS) favored the change of term MRONJ based on growing number of osteonecrosis cases with other antiresorptive (denosumab) and antiangiogenic therapies.[2] The Korean Society for Bone and Mineral Research (KSBMR) and the Korean Association of Oral and Maxillofacial Surgeons (KAOMS) had collectively formed a task force for the preparation of an official statement on MRONJ based on our previous position paper in 2015.[3] The task force reviewed current knowledge and coordinated dental and medical opinions to propose the guideline customized for the local Korean situation.

\section{MRONJ CASE DEFINITION}

In order to differentiate MRONJ from other cases in which treatment is delayed due to other causes, MRONJ is defined according to the following 3 conditions.

A. Current or past use of antiresorptive or antiangiogenic agents

B. Exposure of the jaw bone or intraoral or extraoral fistula persisting for more than 8 weeks

C. No history of head and neck radiation therapy

\section{EPIDEMIOLOGY}

\section{Incidence}

1) Incidence in osteoporosis patients

According to a joint study done by 15 hospitals in Korea with a total of 254 cases of ONJ, in 2008, based on 600,000 patients who were prescribed with BPs, the frequency of BP-related ONJ (BRONJ) was estimated to be $0.04 \%$ (1 in 2,300).[4] The average age of patients was 70 years old (3888 years old), and $21.8 \%$ were due to the intravenous (IV) BPs.[4] According to the recent 4-year study from 2012 to 2014, the cumulative incidence rates of ONJ were 20.9 per 100,000 person-years.[5]

\section{(1) Oral BPs}

In patients administered oral BPs for the treatment of osteoporosis, the incidence was 1.04 to 1.69 per 100,000 patient-years, showing a great variability among the investigators.[6-8]

\section{(2) IV BPs}

The incidence of ONJ when using IV BPs has been reported to be 0 to 90 per 100,000 patient-years.[9-11] In a clinical trial that administered zoledronate as a treatment for osteoporosis for 3 years, the incidence of ONJ was very low at $0.017 \%$. The incidence did not differ greatly in a study that was extended for 3 more years.

\section{(3) Incidence according to the duration of treatment}

In a survey study of Kaiser Permanente members, which included 13,000 subjects, the incidence of ONJ related to oral BP use was $0.1 \%$. However, the incidence increased to $0.21 \%$ in patients who took the drug for more than 4 years. [12] Also, the median duration of BP use was 4.4 years in patients who experienced $\mathrm{ONJ}$, which is longer than the 3.5 years in patients who did not. Summarizing the results of several studies leads to a conclusion that ONJ occurs 100 times more frequently in cancer patients with bone metastasis than in osteoporosis patients.

\section{(4) Denosumab}

It has been known that the incidence of ONJ in patient taking subcutaneous denosumab for the treatment osteoporosis is similar or less than that of ONJ in patients taking BP.[13-15] In the study by the International Task Force on ONJ, the incidence of ONJ in patients with oral and IV BPs were 1.04-69 per 100,000 patients-years and 0-90 per 100,000 patients-years respectively, while that in patients with denosumab was 0-30.2 per 100,000 patients-years.[14]

\section{2) Incidence in cancer patients}

The incidence of ONJ in cancer patients who were administered zoledronate is about $1 \%$, which is 50 to 100 times higher than that seen in the control group $(0-0.019 \% ; 0-1.9$ per 10,000 cancer patients).[16,17] Even in these patients the incidence of ONJ after zoledronate use is $0.6 \%$ for 1 year after, $0.9 \%$ for 2 years after, and $1.3 \%$ for 3 years after, showing an increase according to the duration of use.[1820] The incidence of ONJ in cancer patients who were IV BP 
ranges from 0 to 12,222 per 100,000 patient-years.[14]

\section{Prevalence}

The prevalence of ONJ in osteoporosis patients who have used BPs is known to be $0 \%$ to $0.04 \%$, and most reports show a low prevalence of less than $0.001 \%$. $[6,7,18,21]$ The prevalence of ONJ with the administration of high dose IV BPs is significantly higher than that seen with low dose IV or oral $\mathrm{BP}$, with prevalence rates of $0 \%$ to $0.348 \%$ and the majority being under $0.005 \% .[9,10,22-24]$ And, the prevalence of ONJ with the administration of BP for more than 2 years ranged from $0.05 \%$ to $0.21 \%$ and appeared to be related to the duration of exposure.[25]

\section{PATHOPHYSIOLOGY}

There have been many pre-clinical and clinical studies on the pathophysiology of MRONJ, but the exact mechanism of why osteonecrosis occurs is under investigation. As shown in the definition of MRONJ, the exposure of bone plays an important role in determining the character of the disease.[26] In particular, there are many theories being presented on why this type of osteonecrosis only occurs on the jaw and not in other areas. Several review articles propose a relationship to excessive suppression of the jaw bone turnover, infection/inflammation, angiogenesis inhibition, soft tissue toxicity, the immune system, and accumulation of micro-fractures fractures.[27-30]

\section{Suppression of bone turnover}

BPs inhibit the differentiation and promote apoptosis of osteoclasts, so that the resorption and formation of bone is decreased.[31] Based on the action mechanisms of these medications, it has been reported that bone turnover plays an important role in osteonecrosis.[31,32] The reason why osteonecrosis occurs in the jaw rather than in other long bones is explained by the strong suppression of the bone turnover in jaw bone after experimental BP administration in preclinical study,[33] and more rapid cortical bone turnover in the human alveolar bone than in the long bones. [34] However, there is a contradictory opinion based on the facts that bone turnover is not decreased in the ONJ lesion,[35] osteoclasts exist in the osteonecrotic areas, and that active bone resorption is occurring in these areas.[36]

\section{Infection/inflammation}

It is not clearly defined whether osteonecrosis occurs first and then the necrotic lesion becomes to be infected, or the infected lesion becomes to undergo osteonecrosis. Since the active resorption does not occur in BP-containing bone, the infected tissue is not readily removed completely and can easily progress to chronic osteomyelitis.[37,38] Experimental evidence show that infection and BP administration are necessary and serve as sufficient conditions for osteonecrosis.[39] Moreover, BPs are known to have an effect on the formation of a bacterial biofilm in the lesion. [35]

\section{Angiogenesis inhibition}

BPs have an antiangiogenic effect.[40] Osteonecrosis is regarded as a result of a deficiency in blood supply. Therefore, it has been suggested that angiogenic inhibition may explain the pathophysiology of osteonecrosis.[29,41] However, in animal studies, experimentally induced MRONJ-like lesions did not show vascular insufficiency.[35,42] Moreover, it is difficult to explain why osteonecrosis develops in the circulation-rich upper jaw rather other than long bones. Recently, there have been several reports about ONJ which happened after the administration of antiangiogenic agents (sunitinib or bevacizumab) in cancer patients.[43,44] Additional clinical studies are needed to verify whether angiogenesis inhibition can directly increase the incidence of osteonecrosis.

\section{Soft tissue toxicity}

Although BPs primarily act on osteoclasts, they also have direct toxicity towards soft tissues such as oral epithelial cells. BPs suppress the proliferation and transportation of oral keratinocytes, $[29,45]$ which can increase the chances of latent bone exposure and subsequent infection. Thus, various types of tissue trauma, such as tooth extraction, may create an intraoral lesion and lead to osteonecrosis. [46] However, after reaching the bloodstream, BPs are mostly excreted through the kidneys after a few hr, and the concentration of BPs in tissues other than the bone is reported to be quite low.[47]

\section{Immune-related, or hair-line fracture-related theories}

BPs control the activity of various cells, which involved in 
the immune response. $[48,49]$ The risk of osteonecrosis after tooth extraction becomes significantly higher if steroids [20] or chemotherapeutic agents,[50] which may influence the innate/acquired immune system, are given during BP administration.

Bone tissue is constantly undergoing repetitive microfractures and healing processes throughout life, and such micro-trauma is slowly accumulated by age.[51] Micro-fractures caused by normal mastication are slowly accumulated due to the suppressive effect of BPs on osteoclasts or osteoblasts, resulting in latent osteonecrosis lesions.[52] Bacterial invasion of these lesions may cause progression to a deeper infection.[28,33] The results of various animal studies would support above mentioned hypotheses.[53] However, there are also many contradictory evidences that do not support such theories. Therefore, MRONJ is probably caused by multiple, combined factors that cannot be explained by a single pathophysiologic mechanism.

\section{RISK FACTORS}

\section{Systemic risk factors}

Risk factors of MRONJ can be divided into local or systemic factors. Studies on systemic risk factors for MRONJ are mostly through retrospective analysis, so there are limitations on drawing a definite conclusion. Prospective studies are needed to report on the causality, and factors that have been suggested through studies are as listed below.

\section{1) Duration of antiresorptive treatment}

Risk factors associated with the use of BP include drug potency, administration route (orally or IV), and duration of treatment. However, the dominant factor for the development of MRONJ is the cumulative exposure of the patient to $\mathrm{BP}$, considering both the dose and the frequency. There are many studies that report an increase in the risk of MRONJ as exposure to BP increases. To date, however, no clear threshold below which MRONJ does not occur has been identified. In a survey study of over 13,000 Kaiser Permanente members, the risk of MRONJ in patients with osteoporosis was low during the first 4 years of administration $(0.1 \%)$ and was doubled $(0.21 \%)$ after 4 years.[25] Based on this study, several guidelines suggest 4 years as a threshold, $[2,14]$ but the evidence is insufficient. In Korean studies, MRONJ occurred 2 to 10 years after the use of BPs for the treatment of osteoporosis.[18,54,55]

Denosumab was launched in Korea in 2016 and has since been widely used in the treatment of osteoporosis. In contrast with BP, denosumab does not accumulate in bone and exerts a more transient effect on the inhibition of bone resorption. MRONJ was not reported in the first 3-year randomized controlled trial (RCT) with denosumab in osteoporosis patients,[56] and several cases were reported in subsequent 10-year extension studies.[57]

\section{2) Demographic and lifestyle factor}

Lifestyle and demographic factors, such as increased age, being female, smoking, and obesity, have been reported to be associated with an increased risk of MRONJ. [58] MRONJ shows an increasing trend in patients of old age. It has been reported that the prevalence increases in patients older than 65 years of age,[59] and a similar trend has been reported in local studies, with the highest prevalence seen in patients 70 to 79 years of age.[4] Another Korean study showed that there was no gender difference, and age was an independent risk factor for ARONJ development.[5]

\section{3) Comorbidity and Co-medication}

Most cases of MRONJ occur in association with antiresorptive use in patients with cancer, such as breast cancer, multiple myeloma, prostate cancer, and renal cancer, rather than in patients with osteoporosis.[60] The risk is further increased with concomitant use of glucocorticoids, chemotherapeutic agents, antiangiogenic therapy, or radiation therapy.[13] Diabetes mellitus, rheumatoid arthritis, anemia, hyperthyroidism, dialysis, etc., have been reported as comorbidities that increase the risk. [3,61]

\section{4) Genetic factors}

Pharmacogenomics may influence the risk of developing ONJ. There are reports that polymorphisms in the farnesyl pyrophosphate synthase,[62] cytochrome P450 CYP2C8, [63] VEGFA [64] or SIRT1/HERC4 [65] were significantly associated with a higher risk of ONJ development undergoing BP therapy. Farnesyl pyrophosphate synthase is the enzymatic target of BP and SIRT1 is a molecule involved in the Wnt signaling pathway. Although these reports suggest the possibility of genetic susceptibility to the incidence of MRONJ, how they contribute to ONJ is not well understood. 


\section{Local risk factors}

There are not enough high evidence studies on the local factors of MRONJ incidence. However, tooth extraction, illfitting dentures, torus mandibularis, and infections at the periapical and periodontal areas are frequently mentioned as local risk factors and comorbid conditions in various studies.[61,66,67]

Dental procedures accompanying alveolar bone exposure and damage, such as tooth extraction, dental implant installation, and removal, periodontal and periapical operations, may increase the occurrence of MRONJ and should be cautious in patients being treated with bone modifying agents. $[60,61,66-68]$ Restorative dental treatment, endodontic treatment, and conservative periodontal therapies which do not directly involve alveolar bone tissue are reported to show minimal risk to MRONJ incidence.

Protruded bone surfaces are covered by relatively thin mucosa, and they can be easily irritated by continuous use of dentures or solid food during mastication. The irritated mucosa induces inflammation and bone exposure that contribute to the pathogenesis of MRONJ. Those anatomical conditions that may act as local risk factors include torus mandibularis, torus palatinus, exostosis and the mylohyoid ridge.[69,70] A thick cortical bone structure which has a relatively low blood supply can also be a contributing factor which makes the mandible more prone to MRONJ than the maxilla.

Growing evidences are being suggested to include infections at the periapical and periodontal area as a local risk factor for MRONJ.[66-68,71] Those infections may trigger the occurrence of MRONJ without proper treatment or when treated improperly. Therefore, if the elimination of the dental infection is not possible, extraction should be considered with adequate postoperative care. In addition, infections are commonly the main reason to bring dental extraction or dentoalveolar surgery before the development of MRONJ. Thus, those could be suspected to be responsible for a certain MRONJ occurrence which has blamed tooth extraction to this time.

\section{1) Dentoalveolar surgery that invades or exposes the alveolar bone \\ Tooth extraction, periodontal surgery, Periapical surgery, dental implant installation and removal, torus removal, and alveoloplasty}

\section{2) Local anatomical conditions}

Torus mandibularis, torus palatinus, exostosis, the mylohyoid ridge, and sharp, spiny uneven alveolar bone

\section{3) Concomitant oral disease}

Any infections at the periapical and periodontal area.

\section{MANAGEMENT STRATEGIES - PREVENTION OF MRONJ}

\section{Preventive effects of pre-medication dental consultation}

A multidisciplinary approach is recommended for the management of MRONJ. When considering antiresorptives treatment, there are cases which warrant a dental consult, and appropriate consultation not only decreases the incidence of MRONJ, but also has the advantage of securing the patient's oral health.[42,72-74] There have been numerous studies that show a decrease in MRONJ incidence when a pre-medication dental evaluation is performed before treatment.[75-77] Recent meta-analysis indicated dental preventive measures decreased MRONJ incidence by 77.3\% in 2,332 high-dose cancer patients.[78] Premedication dental evaluation includes baseline oral health examination, periodic check-up, oral care instructions, $0.12 \%$ chlorhexidine rinses, prophylactic periodontal treatment, extraction of the hopeless tooth, and adjustment of dentures.[78] Education about the risk of MRONJ and dental consultation would be helpful to reduce the risk of MRONJ in patients taking BPs who are at high risk for the development of MRONJ.

\section{Drug holiday}

Regarding the necessity of a drug holiday in patients scheduled for dental procedures that require bone recovery such as tooth extraction.

1) Patients taking BPs for the treatment of osteoporosis In the 2011 revised guidelines of the American Dental Association (ADA) Council on Scientific Affairs, the recommendation is that for patients with a BP treatment period of less than 2 years, invasive dental procedures be performed without a drug holiday, [74] while in the International ONJ Task Force guidelines, if the BP treatment period is more than 4 years or if there are concomitant risk factors, a drug 
holiday is recommended until the bone is completely healed. [14] However, according to the 2011 report, the U.S. Food and Drug Administration (FDA)'s stance is that there is not enough evidence yet on the necessity of drug holidays to conclude. In addition, although the necessity of a drug holiday is clear in cases of ONJ, there is little evidence on whether a drug holiday is needed in advance for prevention. AAOMS recommends a drug holiday of 2 months based on a report [79] with evidence in bone physiology and pharmacodynamics. There is no new guideline on the withdrawal for ONJ prevention after that. However, some studies have raised questions about the efficacy of drug withdrawal, and it is crucial to evaluate the risk by considering the administration of BP and other comorbidities. Meanwhile, in a recent study of osteoporotic patients treated with IV and oral $\mathrm{BP}$, there was no difference in the incidence of $\mathrm{ONJ}$ according to the BP administration route.[61] The longer the BPs are taken, the greater the effect of bone accumulation. Therefore conclusively, this committee maintains the previous recommendation that for people taking long-term BPs or concomitant risk factors, BPs should stop for about 2 months before dental treatment and stop until the wound heals after the dental procedure.

\section{2) Patients taking subcutaneous denosumab for the treatment of osteoporosis}

According to the RCT studied so far, there is a report that the risk of ONJ comes out when denosumab is used for more than 3 years. $[56,57]$ Current evidence for ONJ in patients treated with denosumab is mostly based on highdose administration in cancer patients rather than osteoporosis.[80-82] Although consensus in ONJ incidence has not yet been reached, the risk of ONJ in denosumab should also be considered, and caution is required for ONJ in patients receiving denosumab after $\mathrm{BP}$ use.[83] Unlike BP, denosumab is a drug with reversible characteristics, so discontinuation may be highly effective in reducing the risk of developing ONJ.[84] Therefore, the appropriate time for dental treatment can be determined considering the change of bone turnover markers after drug administration, around 5 to 6 months from denosumab administration. It is the time when bone turnover markers such as $\mathrm{C}$-terminal telopeptide of type I collagen (CTX) rise again after denosumab administration.[84] In addition, discontinuation of denosumab increases the risk of rebound fracture.[85]
In conclusion, relevant drug holiday considering the recovery of bone turnover markers for dental treatment is recommended.[67] Given that the association between bone turnover markers and ONJ has not been clearly established yet, it is desirable to judge the above contents at the level of referring to expert opinions. Re-administration of denosumab after invasive dental treatment should be postponed by 2 months until the mucosal and bone healing is completed. It can be usually be done 3 months later than the planned next administration of denosumab.

\section{Biomarkers for MRONJ}

The relation between excessive suppression of CTX and MRONJ occurrence has been widely investigated.[86] However, several clinical studies and recent meta-analysis concluded that CTX values were not associated with MRONJ occurrence.[87,88] Decreased value of CTX would be useful for monitoring dynamic bone resorption and suppression of bone turnover. However, there is not enough evidence to conclude that the degree of CTX suppression has diagnostic value or would be a risk predictor of MRONJ. [89-92] In this regard, other bone markers such as tartrateresistant acid phosphatase $5 \mathrm{~b}$, receptor activator of nuclear factor-KB ligand/osteoprotegerin ratio, and DKK-1 were recently suggested as a possible biomarker for MRONJ,[92,93] however further clinical validation should be followed.

\section{General dental implantation- Simple placement of a dental implant}

The placement of a dental implant and related bone graft has been regarded as a risk factor of the MRONJ. However, a recent systematic review indicated that low-dose oral BP intake for osteoporosis treatment does not compromise implant therapy.[94] Another large cohort study with Korean national health insurance claim data demonstrated that dental implantation was not a risk factor and patients with implants even showed rather lower ratios,[95] indicating general dental implantation would not be contraindicated due to the administration of antiresorptives.

Meanwhile, there have been minority opinions indicating not only the placement of dental implant but also the implant presence-triggered MRONJ, especially in high-dose BPs taking patients.[96-98] Since the limited number of evidences to draw a conclusion is available, further researches are elucidating an association between the dental 
implant and MRONJ.

\section{MANAGEMENT STRATEGIES - STRATEGIES FOR EACH PATIENT GROUP}

\section{Patients scheduled for BP administration for the treatment of osteoporosis}

1) Explanation of the patient on the fact that the risk of MRONJ is low for the time being but becomes higher if the cumulated dose of BP increases as treatment continues due to their long half-life.

2) Although it is not mandatory, the oral examination would be helpful to lower the risk of MRONJ by discovering conditions in which inflammation can easily occur in patients scheduled to receive bone resorption inhibitors such as a BP. Specific guidelines for dental specialists are as follows.[99]

(1) The motivation of the patient on maintaining good oral health

(2) Oral healthcare education, such as dental care, fluorine coating, antibacterial oral rinse, diet, etc.

(3) Evaluation of risk factors for ONJ (mobile teeth, periodontal disease, root remnants, dental caries, periapical lesions, and ill-fitting denture).

(4) Preventive or conservative treatment to maintain functionally healthy teeth

(5) Extraction of teeth with poor prognosis prior to administration of BP.

(6) Consideration of the necessity of complete healing in invasive dental treatment prior to administration of BP (about 4-6 weeks after dental treatment)

(7) Evaluation of patient's wearing dentures

A. Correction of the ill-fitting denture for prevention of mucosal trauma (especially lingual flange or around the mylohyoid ridge)

(8) Regular check-up

(9) Immediate notice in case of symptoms such as pain, swelling, alveolar bone exposure, etc.

(10) Consideration of risk-benefit ratio in the establishment of a treatment plan

\section{Patients receiving oral BPs for the treatment} of osteoporosis with no symptoms of MRONJ Important factors to consider are the duration of BP treat- ment and the presence of clinical risk factors. When the administration of BP is continued for a long time, the risk of ONJ increases due to an increase in the cumulated dose. Although the risk is lower than that seen in cancer patients receiving high dose IV BPs, ONJ can also occur in patients receiving low dose oral BPs for osteoporosis.[100] Because these patients generally show milder symptoms compared to the patients receiving IV BPs, and show a better response to treatment given according to the stage, $[25,86]$ elective dentoalveolar surgery is not prohibited. However, if patients have concomitant risk factors such as steroid use, $[13,101]$ the patient should be considered at high-risk for ONJ. If the patient's performance status allows it, a drug holiday before elective dental surgery should also be considered. $[79,102]$ Once the administration of BP commences, regular dental examination (every 6 months) and education for good oral health are recommended.[103]

Because the value of bone turnover markers, which allow us to estimate the degree of bone formation and resorption, has not been proved yet, $[91,104,105]$ it is not recommended as a tool for estimating risk factors, but further studies are needed.

1) Patients with relatively short-term administration of oral BP with no clinical risk factors

Most dental treatment schedules, including dentoalveolar surgery, do not need to be altered. If a dental implant placement is scheduled and BP treatment is continued, despite the low possibility, the informed consent explaining the increased risk of MRONJ due to BP treatment is recommended. The consent form should include an explanation that even if there are no problems at the time of placement, the implant may fail over a long period and that although the risk of ONJ is very low. For a more thorough consent form, additional supporting clinical studies are needed in the future. Discussion on dose adjustment, drug holiday, or switching to another osteoporosis drug can take place between the BP prescribing physician and the dental specialist.

2) Patients with relatively short-term administration of oral BP but with clinical risk factors such as concomitant use of steroids or angiogenesis inhibitor, diabetes, etc.

The physician prescribing BP and the dental specialist 
may order a drug holiday of more than 2 to 4 months before invasive dental treatment when the patient's systemic condition allows drug holiday.[2] Re-administration of a BP should be done about 2 months after dental treatment when re-epithelization is completed. However, several studies have raised questions about the efficacy of discontinuation of BP (drug holiday) before the invasive dental treatment in preventing MRONJ and have recommended careful considerations of risk and benefit of drug holiday. $[61,106]$

\section{3) Patients with prolonged oral administration of oral $\mathrm{BP}$ regardless of clinical risk factors}

Long-term administration of oral BPs increases the risk of MRONJ due to the high drug accumulation effect. Regarding the cut-off duration for assessing the risk, it is difficult to determine the cut-off duration due to the limited evidence. Despite the limited evidence, several institutions suggested cut-off value for risk of MRONJ through their guidelines. AAOMS committee considers the patients at high risk with extended exposure ( $>4$ years).

After consulting with the BP prescribing physician, if the patients' condition allows it, a drug holiday of at least 2 to 4 months should be taken before dental treatment.[2] Readministration of BP recommends treatment in the same manner as in the aforementioned 'short-term administration of oral BP with clinical risk factors.'[61,106] Further studies are needed on the long-term effects of oral BP treatment.

\section{Patients with established MRONJ}

The efficacy of surgical and conservative treatment has been reported for the various stages of ONJ. The treatment goal for patients who already have progressive ONJ is the alleviation of pain, infection control of the necrotic tissue, and prevention of osteonecrosis progression. MRONJ related to the administration of oral BPs for osteoporosis patients is generally considered to be milder and to have more responsive symptoms to the treatment than those derived from oncologic indication of BPs.[107] Surgical treatment is generally thought to be quite successful, although further progress of necrosis might occur. In cases with advanced stage 3 , surgical treatment should be carefully considered. Where a sequestrum is formed, distinctly the necrotic tissue is easily separated from the surrounding healthy tissue.[108,109] Regardless of the stage, the osteonecrotic area that may irritate the soft tissue and loosely attached necrotic bone fragments should be removed or grinded off so that soft tissue healing is normalized.[110] If symptomatic teeth (teeth that are the cause of pain or that are extremely loose) are attached to the necrotic bone, extraction should be considered, as it is believed not to exacerbate the necrosis. A RCT of hyperbaric oxygen (HBO) showed a possibility as an adjunct therapy,[111] but in the trial, statistical verification was not possible with regard to the major endpoint of the study of 'complete healing of soft tissue', due to small sample size. Therefore, HBO therapy may not be recognized as a sole treatment method for MRONJ, and further study results should be followed. There are numerous case studies being reported on adjunct methods such as platelet-rich plasma treatment,[112,113] laser treatment,[114] parathyroid hormone (PTH) treatment, $[115,116]$ bone morphogenetic protein treatment,[117,118] etc. but none are fully proven yet.

\section{Staging and treatment strategy for patients with established MRONJ}

Since the AAOMS added a stage 0 to Position Paper in 2009, several committees included a stage 0 in their guidelines. $[2,3,61,103]$ Given that close to $50 \%$ of all cases in this stage progress to a higher stage, the addition of stage 0 appears to be valid.[119,120] In contrast, the International Task Force on ONJ suggests that inclusion of stage 0 to staging system may lead to overdiagnosis of MRONJ, and subsequently modifying or discontinuing treatment with BPs or anti-resorptive drug to prevent progression to MRONJ could have detrimental results.[14] Following this concern, the Multinational Association of Supportive Care in Cancer/International Society of Oral Oncology (MASCC/ISOO) and American Society of Clinical Oncology (ASCO) suggests stage 0 as an increased risk stage. It uses the terminology 'increased risk' in its staging system.[121]

This position paper includes stage 0 in the staging system as in the AAOMS staging system. However, given the overdiagnosis aspect of MRONJ, special caution is recommended when diagnosing patients with non-specific symptoms, that is previously stage 0 patients.

\section{1) At risk}

Patients that are taking oral or IV antiresorptive or antiangiogenic drug or who, although have no exposure of necrotic bone, are exposed to BPs or have a history of BP 
exposure. Education on the risk of ONJ occurrence and oral hygiene should be emphasized with the control of risk factors.

\section{2) Stage 1}

\section{(1) Symptoms}

Osteonecrosis with bone exposure or fistula that reaches the bone during probing, with no signs and symptoms of infection. Radiographic findings that are seen in Stage 0 may be presented.

\section{(2) Treatment strategy}

Antibacterial oral rinse can be helpful and immediate surgery is not necessary.

\section{3) Stage 2}

\section{(1) Symptoms}

Osteonecrosis with bone exposure or fistula that reaches the bone during probing, with signs and symptoms of infection (pain and erythema of the area of osteonecrosis). Radiographic findings that are seen in Stage 0 may be presented.

\section{(2) Treatment strategy}

Antibacterial oral rinse and antibiotics must be prescribed. Although the infection is not the main cause of ONJ, bacterial accumulation in the necrotic area is commonly observed and is usually controlled by penicillin. The formation of a bacterial membrane in the mouth is common and may also occur in the necrotic area. This membrane has been reported to interfere with the efficacy of systemic antibiotics. Besides this, pain control with analgesics and removal of sequestrum that irritate the soft tissue is also possible.

\section{4) Stage 3}

\section{(1) Symptoms}

Osteonecrosis with bone exposure or fistula that reaches the bone during probing, with signs and symptoms of infection (pain and erythema of the area of osteonecrosis), and the presence of the following symptoms:

A. The extension of osteonecrosis beyond the alveolar bone (mandibular inferior border, maxillary sinus, etc.)

B. Pathological fractures

C. Orocutaneous fistula
D. Oronasal- and oroantral fistula

E. Osteolysis extending to the mandibular inferior border or the base of the maxillary sinus

\section{(2) Treatment strategy}

Pain control, oral antibacterial rinse, and infection control through antibiotic treatment are required, and for the long-term alleviation of infection or pain, surgical debridement or resection is necessary. If a sequestrum is distinctly formed so that the tissue is easily separated from the surrounding healthy tissue, or if there is a tooth in the middle of the sequestrum, the necrotic bone is not exacerbated by extraction. Therefore, any mobile bone fragments or teeth should be removed. Because there may be cancer metastasis, the removed bone fragments should be examined. Immediate reconstruction after surgical resection has been reported, but clinicians must decide after thoroughly considering the patient's condition.

\section{5) Discontinuation and Timing of Resumption of antiresorptive therapy in patients undergoing treatment for MRONJ}

Anti-resorptive therapy needs to be discontinued until the treatment of MRONJ is completed. Hinson et al. reported that patients who discontinued BPs before or at treatment initiation of MRONJ had faster resolution of MRONJ symptoms by 6 months compared with continuing BPs. [122]

\section{MEDICAL MANAGEMENT OF PATIENTS WITH MRONJ}

\section{Recombinant human PTH 1-34 (teriparatide) treatment}

Teriparatide stimulates osteoblasts and osteoclasts while inhibiting the apoptosis of osteoblasts, showing an increase in bone density and excellent efficacy in preventing fractures.[123,124] The bone remodeling stimulatory effect of teriparatide has been shown to be effective even in patients with suppressed bone remodeling processes due to the use of bone resorption inhibitors such as BPs.[125]

There have been many reports that teriparatide may play a positive role in the treatment of ONJ. In 2010 Cheung and Seeman [126] treated an ONJ patient with teriparatide for 8 weeks, upon which the patient's symptoms improved 
and the ONJ area healed completely, leading the authors to report that teriparatide is effective as a treatment for ONJ. Also, another study was reported in that similar period in which teriparatide injection treatment was given for 6 weeks to patients with gingivitis who had pathological findings similar to $\mathrm{ONJ}$, and the patients who received treatment showed improvement of markers related to gingivitis recovery compared to those who did not receive treatment. [116] Studies in Korea have shown that clinical improvement of ONJ was better in patients treated with teriparatide.[127-129] Fifteen patients with ONJ were given teriparatide for 6 months and were compared with 9 patients unable to receive teriparatide. While $40 \%$ of non-teriparatide groups did not show any improvement of ONJ lesion, all teriparatide-treated patients showed improvement of ONJ lesion, and $38 \%$ of patients have 2 stages of improvement or complete healing.[128] Recently, Sim et al. [130] conducted double-blind RCT and found that teriparatide promotes bone healing in cancer or osteoporosis patients with established MRONJ. Teriparatide ( $20 \mu \mathrm{g} /$ day) or placebo was given for 8 weeks and observed for 12 months in 34 patients with MRONJ. Primary outcomes were clinical and radiologic resolution of MRONJ. The teriparatide group showed a greater rate of resolution of MRONJ lesions than a placebo group. Also, $45.4 \%$ of MRONJ lesions in the teriparatide group and $33.3 \%$ in the placebo group resolved during 12 months $(P<0.05)$.

Through such various clinical studies, including small $\mathrm{RCT}$, there is increasing evi-dence on the positive role of teriparatide in the treatment of ONJ patients. This effect is seen not only due to the stimulatory effect on the bone remodeling of teriparatide but also due to its stimulation of angiogenesis.[131] Furthermore, when taking into account the fact that ONJ patients are also osteoporosis patients, the use of teriparatide is also beneficial when seen from the perspective of osteoporosis treatment.

Due to a possible increase in the incidence of osteosarcoma, teriparatide is cautiously used in patients with bone metastatic cancer. Meanwhile, a 15-year post-marketing surveillance study and Forteo Patient Registry Surveillance study demonstrated that the incidence of osteosarcoma associated with teriparatide use was no different than would be expected based on the background incidence rate of osteosarcoma.[132,133] Moreover, a recent study demonstrated the effectiveness of teriparatide for MRONJ in ma- lignant bone disease patients [130] that might contribute to changing labels with further evidence.

\section{Vitamin D and calcium}

Appropriate vitamin $\mathrm{D}$ and calcium intake are the basic fundamentals of osteoporosis prevention and treatment. Therefore, although ONJ patients may discontinue BP, appropriate vitamin $D$ and calcium supplementation should be continued. Certain recent studies have shown that the concentration of serum vitamin $D$ is positively correlated to the amelioration of gingivitis or the degree of recovery after gingival surgery, and the maintenance of an appropriate concentration of vitamin $D$ is thought to be important for the recovery of ONJ.[126,127] Even when using the previously introduced teriparatide for ONJ treatment, an appropriate vitamin $\mathrm{D}$ level has been reported to be a factor that can increase the effect of the drug.[124] Therefore, ONJ patients must continue supplementation of vitamin $D$ and calcium for the amelioration of gingivitis or the prevention of osteoporosis.

\section{CONCLUSIONS}

BPs are effective drugs for treating osteoporosis and preventing fractures. Although the incidence rate is very low, MRONJ can occur when BPs are administered for a long period. Discontinuation of BP treatment is recommended if MRONJ occurs. In cases of BP discontinuation, drug replacements may be considered according to individual patient conditions such as malignant bone metastasis or osteoporosis. However, the efficacy or relation to ONJ recovery of such replacements has not been proven through large-scale clinical studies; therefore, a careful approach is necessary.

MRONJ cases that might be related to denosumab were reported. Mostly high dose therapy was associated with MRONJ occurrence, although some cases were observed during osteoporosis treatment. However, more evidence would be necessary to corroborate this.

Basic conservative treatment and surgery are all possible for the treatment of ONJ. Despite such dental treatments, if ONJ has progressed, teriparatide, a bone formation accelerator, may help with the recovery of ONJ. Vitamin D concentration is known to be related to gingivitis or gum recovery; therefore, vitamin $\mathrm{D}$ and calcium supplementation 
can prevent not only the exacerbation of osteoporosis but should be continued in that it can also help in the treatment of ONJ.

\section{DECLARATIONS}

\section{Ethics approval and consent to participate Not applicable.}

\section{Conflict of interest}

No potential conflict of interest relevant to this article was reported.

\section{ORCID}

Jin-Woo Kim https://orcid.org/0000-0002-1672-5730

Mi Kyung Kwak https://orcid.org/0000-0002-8092-2560 Jeong Joon Han https://orcid.org/0000-0001-8975-0198 Sung-Tak Lee Ha Young Kim Se Hwa Kim https://orcid.org/0000-0001-6651-8046 https://orcid.org/0000-0002-0651-2213 https://orcid.org/0000-0003-2452-8419 Junho Jung https://orcid.org/0000-0002-7007-0974 Jeong Keun Lee https://orcid.org/0000-0002-5561-6297 Young-Kyun Lee https://orcid.org/0000-0001-6564-4294 Yong-Dae Kwon https://orcid.org/0000-0001-9620-4814 Deog-Yoon Kim https://orcid.org/0000-0003-4054-0231

\section{REFERENCES}

1. Marx RE. Pamidronate (Aredia) and zoledronate (Zometa) induced avascular necrosis of the jaws: a growing epidemic. J Oral Maxillofac Surg 2003;61:1115-7. https:// doi.org/10.1016/s0278-2391(03)00720-1.

2. Ruggiero SL, Dodson TB, Fantasia J, et al. American Association of Oral and Maxillofacial Surgeons position paper on medication-related osteonecrosis of the jaw-2014 update. J Oral Maxillofac Surg 2014;72:1938-56. https:// doi.org/10.1016/j.joms.2014.04.031.

3. Kim KM, Rhee Y, Kwon YD, et al. Medication related osteonecrosis of the jaw: 2015 position statement of the Korean Society for Bone and Mineral Research and the Korean Association of Oral and Maxillofacial Surgeons. J Bone Metab 2015;22:151-65. https://doi.org/10.11005/ jbm.2015.22.4.151.

4. Lee JK, Kim KW, Choi JY, et al. Bisphosphonates-related osteonecrosis of the jaw in Korea: a preliminary report. J
Korean Assoc Oral Maxillofac Surg 2013;39:9-13. https:// doi.org/10.5125/jkaoms.2013.39.1.9.

5. Kim SH, Lee YK, Kim TY, et al. Incidence of and risk for osteonecrosis of the jaw in Korean osteoporosis patients treated with bisphosphonates: A nationwide cohortstudy. Bone 2021;143:115650. https://doi.org/10.1016/ j.bone.2020.115650.

6. Khan AA, Rios LP, Sándor GK, et al. Bisphosphonate-associated osteonecrosis of the jaw in Ontario: a survey of oral and maxillofacial surgeons. J Rheumatol 2011;38: 1396-402. https://doi.org/10.3899/jrheum.100221.

7. Ulmner M, Jarnbring F, Törring 0 . Osteonecrosis of the jaw in Sweden associated with the oral use of bisphosphonate. J Oral Maxillofac Surg 2014;72:76-82. https:// doi.org/10.1016/j.joms.2013.06.221.

8. Etminan M, Aminzadeh K, Matthew IR, et al. Use of oral bisphosphonates and the risk of aseptic osteonecrosis: $a$ nested case-control study. J Rheumatol 2008;35:691-5.

9. Lyles KW, Colón-Emeric CS, Magaziner JS, et al. Zoledronic acid and clinical fractures and mortality after hip fracture. N Engl J Med 2007;357:1799-809. https://doi. org/10.1056/NEJMoa074941.

10. Sieber P, Lardelli P, Kraenzlin CA, et al. Intravenous bisphosphonates for postmenopausal osteoporosis: safety profiles of zoledronic acid and ibandronate in clinical practice. Clin Drug Investig 2013;33:117-22. https://doi.org/ 10.1007/s40261-012-0041-1.

11. Tennis P, Rothman KJ, Bohn RL, et al. Incidence of osteonecrosis of the jaw among users of bisphosphonates with selected cancers or osteoporosis. Pharmacoepidemiol Drug Saf 2012;21:810-7. https://doi.org/10.1002/ pds.3292.

12. Malden N, Lopes V. An epidemiological study of alendronate-related osteonecrosis of the jaws. A case series from the south-east of Scotland with attention given to case definition and prevalence. J Bone Miner Metab 2012;30: 171-82. https://doi.org/10.1007/s00774-011-0299-z.

13. Saad F, Brown JE, Van Poznak C, et al. Incidence, risk factors, and outcomes of osteonecrosis of the jaw: integrated analysis from three blinded active-controlled phase III trials in cancer patients with bone metastases. Ann Oncol 2012;23:1341-7. https://doi.org/10.1093/annonc/ mdr435.

14. Khan AA, Morrison A, Hanley DA, et al. Diagnosis and management of osteonecrosis of the jaw: a systematic 
review and international consensus. J Bone Miner Res 2015;30:3-23. https://doi.org/10.1002/jbmr.2405.

15. Sugimoto T, Matsumoto T, Hosoi T, et al. Three-year denosumab treatment in postmenopausal Japanese women and men with osteoporosis: results from a 1-year openlabel extension of the Denosumab Fracture Intervention Randomized Placebo Controlled Trial (DIRECT). Osteoporos Int 2015;26:765-74. https://doi.org/10.1007/s00198014-2964-2.

16. Amadori D, Aglietta M, Alessi B, et al. Efficacy and safety of 12-weekly versus 4-weekly zoledronic acid for prolonged treatment of patients with bone metastases from breast cancer (ZOOM): a phase 3, open-label, randomised, noninferiority trial. Lancet Oncol 2013;14:663-70. https:// doi.org/10.1016/s1470-2045(13)70174-8.

17. Bamias A, Kastritis E, Bamia C, et al. Osteonecrosis of the jaw in cancer after treatment with bisphosphonates: incidence and risk factors. J Clin Oncol 2005;23:8580-7. https://doi.org/10.1200/jco.2005.02.8670.

18. Hong JW, Nam W, Cha IH, et al. Oral bisphosphonate-related osteonecrosis of the jaw: the first report in Asia. Osteoporos Int 2010;21:847-53. https://doi.org/10.1007/ s00198-009-1024-9.

19. Hoff $A O$, Toth BB, Altundag $K$, et al. Frequency and risk factors associated with osteonecrosis of the jaw in cancer patients treated with intravenous bisphosphonates. J Bone Miner Res 2008;23:826-36. https://doi.org/10.1359/ jbmr.080205.

20. Jadu $F$, Lee $L$, Pharoah $M$, et al. A retrospective study assessing the incidence, risk factors and comorbidities of pamidronate-related necrosis of the jaws in multiple myeloma patients. Ann Oncol 2007;18:2015-9. https://doi. org/10.1093/annonc/mdm370.

21. Urade M, Tanaka N, Furusawa K, et al. Nationwide survey for bisphosphonate-related osteonecrosis of the jaws in Japan. J Oral Maxillofac Surg 2011;69:e364-71. https:// doi.org/10.1016/j.joms.2011.03.051.

22. Cartsos VM, Zhu S, Zavras Al. Bisphosphonate use and the risk of adverse jaw outcomes: a medical claims study of 714,217 people. J Am Dent Assoc 2008;139:23-30. https: //doi.org/10.14219/jada.archive.2008.0016.

23. Fellows JL, Rindal DB, Barasch A, et al. ONJ in two dental practice-based research network regions. J Dent Res 2011; 90:433-8. https://doi.org/10.1177/0022034510387795.

24. Powell D, Bowler C, Roberts $T$, et al. Incidence of serious side effects with intravenous bisphosphonate: a clinical audit. QJM 2012;105:965-71. https://doi.org/10.1093/ qjmed/hcs112.

25. Lo JC, O'Ryan FS, Gordon NP, et al. Prevalence of osteonecrosis of the jaw in patients with oral bisphosphonate exposure. J Oral Maxillofac Surg 2010;68:243-53. https:// doi.org/10.1016/j.joms.2009.03.050.

26. Advisory Task Force on Bisphosphonate-Related Ostenonecrosis of the Jaws, American Association of Oral and Maxillofacial Surgeons. American Association of Oral and Maxillofacial Surgeons position paper on bisphosphonate-related osteonecrosis of the jaws. J Oral Maxillofac Surg 2007;65:369-76. https://doi.org/10.1016/j.joms.2006. 11.003.

27. Yoneda $T$, Hagino $H$, Sugimoto $T$, et al. Bisphosphonaterelated osteonecrosis of the jaw: position paper from the Allied Task Force Committee of Japanese Society for Bone and Mineral Research, Japan Osteoporosis Society, Japanese Society of Periodontology, Japanese Society for Oral and Maxillofacial Radiology, and Japanese Society of Oral and Maxillofacial Surgeons. J Bone Miner Metab 2010;28:365-83. https://doi.org/10.1007/s00774-0100162-7.

28. Subramanian G, Fritton JC, Quek SY. Osteonecrosis and atypical fractures-common origins? Osteoporos Int 2013; 24:745-6. https://doi.org/10.1007/s00198-012-1953-6.

29. Landesberg R, Woo V, Cremers S, et al. Potential pathophysiological mechanisms in osteonecrosis of the jaw. Ann N Y Acad Sci 2011;1218:62-79. https://doi.org/10. 1111/j.1749-6632.2010.05835.x.

30. Hoefert S, Schmitz I, Tannapfel A, et al. Importance of microcracks in etiology of bisphosphonate-related osteonecrosis of the jaw: a possible pathogenetic model of symptomatic and non-symptomatic osteonecrosis of the jaw based on scanning electron microscopy findings. Clin Oral Investig 2010;14:271-84. https://doi.org/10.1007/ s00784-009-0300-6.

31. Russell RG, Watts NB, Ebetino FH, et al. Mechanisms of action of bisphosphonates: similarities and differences and their potential influence on clinical efficacy. Osteoporos Int 2008;19:733-59. https://doi.org/10.1007/s00198007-0540-8.

32. Allen MR. Bisphosphonates and osteonecrosis of the jaw: moving from the bedside to the bench. Cells Tissues Organs 2009;189:289-94. https://doi.org/10.1159/000151371. 
33. Allen MR. The effects of bisphosphonates on jaw bone remodeling, tissue properties, and extraction healing. Odontology 2011;99:8-17. https://doi.org/10.1007/s10266010-0153-0.

34. Allen MR, Kubek DJ, Burr DB. Cancer treatment dosing regimens of zoledronic acid result in near-complete suppression of mandible intracortical bone remodeling in beagle dogs. J Bone Miner Res 2010;25:98-105. https:// doi.org/10.1359/jbmr.090713.

35. Lesclous P, Abi Najm S, Carrel JP, et al. Bisphosphonateassociated osteonecrosis of the jaw: a key role of inflammation? Bone 2009;45:843-52. https://doi.org/10.1016/ j.bone.2009.07.011.

36. O'Ryan FS, Khoury S, Liao W, et al. Intravenous bisphosphonate-related osteonecrosis of the jaw: bone scintigraphy as an early indicator. J Oral Maxillofac Surg 2009; 67:1363-72. https://doi.org/10.1016/j.joms.2009.03.005.

37. Sedghizadeh PP, Kumar SK, Gorur A, et al. Microbial biofilms in osteomyelitis of the jaw and osteonecrosis of the jaw secondary to bisphosphonate therapy. J Am Dent Assoc 2009;140:1259-65. https://doi.org/10.14219/jada. archive.2009.0049.

38. Aspenberg P. Osteonecrosis of the jaw: what do bisphosphonates do? Expert Opin Drug Saf 2006;5:743-5. https: //doi.org/10.1517/14740338.5.6.743.

39. Aspenberg P, Genant HK, Johansson T, et al. Teriparatide for acceleration of fracture repair in humans: a prospective, randomized, double-blind study of 102 postmenopausal women with distal radial fractures. J Bone Miner Res 2010;25:404-14. https://doi.org/10.1359/jbmr.090731.

40. Santini D, Vincenzi B, Dicuonzo G, et al. Zoledronic acid induces significant and long-lasting modifications of circulating angiogenic factors in cancer patients. Clin Cancer Res 2003;9:2893-7.

41. Allen MR, Burr DB. The pathogenesis of bisphosphonaterelated osteonecrosis of the jaw: so many hypotheses, so few data. J Oral Maxillofac Surg 2009;67:61-70. https: //doi.org/10.1016/j.joms.2009.01.007.

42. Yamashita J, Koi K, Yang DY, et al. Effect of zoledronate on oral wound healing in rats. Clin Cancer Res 2011;17: 1405-14. https://doi.org/10.1158/1078-0432.Ccr-10-1614.

43. Hoefert $\mathrm{S}$, Eufinger $\mathrm{H}$. Sunitinib may raise the risk of bisphosphonate-related osteonecrosis of the jaw: presentation of three cases. Oral Surg Oral Med Oral Pathol Oral Radiol Endod 2010;110:463-9. https://doi.org/10.1016/ j.tripleo.2010.04.049.

44. Wynn RL. Bevacizumab (Avastin): An anti-angiogenic drug associated with osteonecrosis of the jaw. Gen Dent 2011;59:410-3.

45. Yamashita J, McCauley LK. Antiresorptives and osteonecrosis of the jaw. J Evid Based Dent Pract 2012;12:23347. https://doi.org/10.1016/s1532-3382(12)70046-5.

46. Reid IR. Osteonecrosis of the jaw: who gets it, and why? Bone 2009;44:4-10. https://doi.org/10.1016/j.bone.2008. 09.012.

47. Reid IR, Cornish J. Epidemiology and pathogenesis of osteonecrosis of the jaw. Nat Rev Rheumatol 2011;8:90-6. https://doi.org/10.1038/nrrheum.2011.181.

48. Oizumi T, Funayama $H$, Yamaguchi K, et al. Inhibition of necrotic actions of nitrogen-containing bisphosphonates (NBPs) and their elimination from bone by etidronate (a non-NBP): a proposal for possible utilization of etidronate as a substitution drug for NBPs. J Oral Maxillofac Surg 2010;68:1043-54. https://doi.org/10.1016/j.joms.2009. 08.027.

49. Corrado A, Santoro N, Cantatore FP. Extra-skeletal effects of bisphosphonates. Joint Bone Spine 2007;74:32-8. https: //doi.org/10.1016/j.jbspin.2006.06.005.

50. Thumbigere-Math V, Tu L, Huckabay S, et al. A retrospective study evaluating frequency and risk factors of osteonecrosis of the jaw in 576 cancer patients receiving intravenous bisphosphonates. Am J Clin Oncol 2012;35:38692. https://doi.org/10.1097/COC.0b013e3182155fcb.

51. Allen MR, Iwata K, Phipps R, et al. Alterations in canine vertebral bone turnover, microdamage accumulation, and biomechanical properties following 1-year treatment with clinical treatment doses of risedronate or alendronate. Bone 2006;39:872-9. https://doi.org/10.1016/j.bone. 2006.04.028.

52. Compston J. Pathophysiology of atypical femoral fractures and osteonecrosis of the jaw. Osteoporos Int 2011; 22:2951-61. https://doi.org/10.1007/s00198-011-1804-x.

53. Kim JW, Landayan ME, Lee JY, et al. Role of microcracks in the pathogenesis of bisphosphonate-related osteonecrosis of the jaw. Clin Oral Investig 2016;20:2251-8. https://doi.org/10.1007/s00784-016-1718-2.

54. Kwon YD, Lee DW, Choi BJ, et al. Short-term teriparatide therapy as an adjunctive modality for bisphosphonaterelated osteonecrosis of the jaws. Osteoporos Int 2012; 23:2721-5. https://doi.org/10.1007/s00198-011-1882-9. 
55. Park W, Kim NK, Kim MY, et al. Osteonecrosis of the jaw induced by oral administration of bisphosphonates in Asian population: five cases. Osteoporos Int 2010;21:52733. https://doi.org/10.1007/s00198-009-0973-3.

56. Cummings SR, San Martin J, McClung MR, et al. Denosumab for prevention of fractures in postmenopausal women with osteoporosis. N Engl J Med 2009;361:75665. https://doi.org/10.1056/NEJMoa0809493.

57. Bone HG, Wagman RB, Brandi ML, et al. 10 years of denosumab treatment in postmenopausal women with osteoporosis: results from the phase 3 randomised FREEDOM trial and open-label extension. Lancet Diabetes Endocrinol 2017;5:513-23. https://doi.org/10.1016/s22138587(17)30138-9.

58. Inada A, Hosohata K, Oyama S, et al. Evaluation of medication-related osteonecrosis of the jaw using the Japanese Adverse Drug Event Report database. Ther Clin Risk Manag 2019;15:59-64. https://doi.org/10.2147/tcrm. S176620.

59. Yamazaki T, Yamori M, Ishizaki T, et al. Increased incidence of osteonecrosis of the jaw after tooth extraction in patients treated with bisphosphonates: a cohort study. Int J Oral Maxillofac Surg 2012;41:1397-403. https://doi.org/ 10.1016/j.jom.2012.06.020.

60. McGowan K, McGowan T, Ivanovski S. Risk factors for medication-related osteonecrosis of the jaws: A systematic review. Oral Dis 2018;24:527-36. https://doi.org/10.1111/ odi.12708.

61. Yoneda $T$, Hagino $H$, Sugimoto $T$, et al. Antiresorptive agent-related osteonecrosis of the jaw: Position Paper 2017 of the Japanese Allied Committee on Osteonecrosis of the Jaw. J Bone Miner Metab 2017;35:6-19. https:// doi.org/10.1007/s00774-016-0810-7.

62. Marini F, Tonelli P, Cavalli L, et al. Pharmacogenetics of bisphosphonate-associated osteonecrosis of the jaw. Front Biosci (Elite Ed) 2011;3:364-70. https://doi.org/10.2741/ e251.

63. English BC, Baum CE, Adelberg DE, et al. A SNP in CYP2C8 is not associated with the development of bisphosphonate-related osteonecrosis of the jaw in men with castrate-resistant prostate cancer. Ther Clin Risk Manag 2010; 6:579-83. https://doi.org/10.2147/tcrm.S14303.

64. Kim JW, Yee J, Oh SH, et al. Machine learning approaches for predicting bisphosphonate-related osteonecrosis in women with osteoporosis using VEGFA gene polymor- phisms. J Pers Med 2021;11:541. https://doi.org/10.3390/ jpm11060541.

65. Yang G, Hamadeh IS, Katz J, et al. SIRT1/HERC4 locus associated with bisphosphonate-induced osteonecrosis of the jaw: an exome-wide association analysis. J Bone Miner Res 2018;33:91-8. https://doi.org/10.1002/jbmr.3285.

66. Ueda N, Aoki K, Shimotsuji H, et al. Oral risk factors associated with medication-related osteonecrosis of the jaw in patients with cancer. J Bone Miner Metab 2021;39:62330. https://doi.org/10.1007/s00774-020-01195-x.

67. Campisi G, Mauceri R, Bertoldo F, et al. Medication-related osteonecrosis of jaws (MRONJ) prevention and diagnosis: Italian Consensus Update 2020. Int J Environ Res Public Health 2020;17:5998. https://doi.org/10.3390/ ijerph17165998.

68. Ueda N, Nakashima C, Aoki K, et al. Does inflammatory dental disease affect the development of medicationrelated osteonecrosis of the jaw in patients using highdose bone-modifying agents? Clin Oral Investig 2021;25: 3087-93. https://doi.org/10.1007/s00784-020-03632-7.

69. Choi WS, Lee JI, Yoon HJ, et al. Medication-related osteonecrosis of the jaw: a preliminary retrospective study of 130 patients with multiple myeloma. Maxillofac Plast Reconstr Surg 2017;39:1. https://doi.org/10.1186/s40902016-0099-4.

70. Niibe K, Ouchi T, Iwasaki R, et al. Osteonecrosis of the jaw in patients with dental prostheses being treated with bisphosphonates or denosumab. J Prosthodont Res 2015; 59:3-5. https://doi.org/10.1016/j.jpor.2014.08.001.

71. Nicolatou-Galitis O, Papadopoulou E, Vardas E, et al. Alveolar bone histological necrosis observed prior to extractions in patients, who received bone-targeting agents. Oral Dis 2020;26:955-66. https://doi.org/10.1111/odi.13294.

72. Smidt-Hansen T, Folkmar TB, Fode K, et al. Combination of zoledronic Acid and targeted therapy is active but may induce osteonecrosis of the jaw in patients with metastatic renal cell carcinoma. J Oral Maxillofac Surg 2013;71: 1532-40. https://doi.org/10.1016/j.joms.2013.03.019.

73. Epstein MS, Epstein JB, Ephros HD. The effects of osteoclast modifiers on the oral cavity: a review for prescribers. Curr Opin Support Palliat Care 2012;6:337-41. https:// doi.org/10.1097/SPC.0b013e3283560646.

74. Hellstein JW, Adler RA, Edwards B, et al. Managing the care of patients receiving antiresorptive therapy for prevention and treatment of osteoporosis: executive sum- 
mary of recommendations from the American Dental Association Council on Scientific Affairs. J Am Dent Assoc 2011;142:1243-51. https://doi.org/10.14219/jada.archive.2011.0108.

75. Dimopoulos MA, Kastritis E, Bamia C, et al. Reduction of osteonecrosis of the jaw (ONJ) after implementation of preventive measures in patients with multiple myeloma treated with zoledronic acid. Ann Oncol 2009;20:117-20. https://doi.org/10.1093/annonc/mdn554.

76. Ripamonti Cl, Maniezzo M, Campa T, et al. Decreased occurrence of osteonecrosis of the jaw after implementation of dental preventive measures in solid tumour patients with bone metastases treated with bisphosphonates. The experience of the National Cancer Institute of Milan. Ann Oncol 2009;20:137-45. https://doi.org/10.1093/ annonc/mdn526.

77. Bonacina R, Mariani U, Villa F, et al. Preventive strategies and clinical implications for bisphosphonate-related osteonecrosis of the jaw: a review of 282 patients. J Can Dent Assoc 2011;77:b147.

78. Karna H, Gonzalez J, Radia HS, et al. Risk-reductive dental strategies for medication related osteonecrosis of the jaw among cancer patients: A systematic review with meta-analyses. Oral Oncol 2018;85:15-23. https://doi. org/10.1016/j.oraloncology.2018.08.003.

79. Damm DD, Jones DM. Bisphosphonate-related osteonecrosis of the jaws: a potential alternative to drug holidays. Gen Dent 2013;61:33-8.

80. Taylor KH, Middlefell LS, Mizen KD. Osteonecrosis of the jaws induced by anti-RANK ligand therapy. Br J Oral Maxillofac Surg 2010;48:221-3. https://doi.org/10.1016/j.bjoms. 2009.08.030.

81. Aghaloo TL, Felsenfeld AL, Tetradis S. Osteonecrosis of the jaw in a patient on Denosumab. J Oral Maxillofac Surg 2010;68:959-63. https://doi.org/10.1016/j.joms.2009.10.010.

82. Stopeck AT, Fizazi K, Body JJ, et al. Safety of long-term denosumab therapy: results from the open label extension phase of two phase 3 studies in patients with metastatic breast and prostate cancer. Support Care Cancer 2016;24:447-55. https://doi.org/10.1007/s00520-0152904-5.

83. Srivastava A, Nogueras Gonzalez GM, Geng Y, et al. Prevalence of medication related osteonecrosis of the jaw in patients treated with sequential antiresorptive drugs: systematic review and meta-analysis. Support Care Can- cer 2021;29:2305-17. https://doi.org/10.1007/s00520020-05882-3.

84. Bone HG, Bolognese MA, Yuen CK, et al. Effects of denosumab treatment and discontinuation on bone mineral density and bone turnover markers in postmenopausal women with low bone mass. J Clin Endocrinol Metab 2011;96:972-80. https://doi.org/10.1210/jc.2010-1502.

85. Cummings SR, Ferrari S, Eastell R, et al. Vertebral fractures after discontinuation of denosumab: a post hoc analysis of the randomized placebo-controlled FREEDOM trial and its extension. J Bone Miner Res 2018;33:190-8. https:// doi.org/10.1002/jbmr.3337.

86. Marx RE, Cillo JE, Jr., Ulloa JJ. Oral bisphosphonate-induced osteonecrosis: risk factors, prediction of risk using serum CTX testing, prevention, and treatment. J Oral Maxillofac Surg 2007;65:2397-410. https://doi.org/10.1016/j.joms. 2007.08.003.

87. Awad ME, Sun C, Jernigan J, et al. Serum C-terminal crosslinking telopeptide level as a predictive biomarker of osteonecrosis after dentoalveolar surgery in patients receiving bisphosphonate therapy: Systematic review and meta-analysis. J Am Dent Assoc 2019;150:664-75.e8. https: //doi.org/10.1016/j.adaj.2019.03.006.

88. Kim JW, Kong KA, Kim SJ, et al. Prospective biomarker evaluation in patients with osteonecrosis of the jaw who received bisphosphonates. Bone 2013;57:201-5. https:// doi.org/10.1016/j.bone.2013.08.005.

89. Bagan JV, Jiménez Y, Gómez D, et al. Collagen telopeptide (serum (TX) and its relationship with the size and number of lesions in osteonecrosis of the jaws in cancer patients on intravenous bisphosphonates. Oral Oncol 2008;44:1088-9. https://doi.org/10.1016/j.oraloncology.2008.01.012.

90. Kwon YD, Ohe JY, Kim DY, et al. Retrospective study of two biochemical markers for the risk assessment of oral bisphosphonate-related osteonecrosis of the jaws: can they be utilized as risk markers? Clin Oral Implants Res 2011;22:100-5. https://doi.org/10.1111/j.1600-0501.2010. 01965.x

91. Kwon YD, Kim DY, Ohe JY, et al. Correlation between serum C-terminal cross-linking telopeptide of type I collagen and staging of oral bisphosphonate-related osteonecrosis of the jaws. J Oral Maxillofac Surg 2009;67:26448. https://doi.org/10.1016/j.joms.2009.04.067.

92. Kim JW, Cha IH, Kim SJ, et al. Biomarkers for bisphospho- 
nate-related osteonecrosis of the jaw. Clin Implant Dent Relat Res 2016;18:281-91. https://doi.org/10.1111/cid. 12297.

93. Park JH, Cho S, Kim SJ, et al. Serum biomarkers for bisphosphonate-related osteonecrosis of the jaw: a prospective clinical study. Osteoporos Int 2021. https://doi.org/10.1007/ s00198-021-06137-5.

94. Stavropoulos A, Bertl K, Pietschmann P, et al. The effect of antiresorptive drugs on implant therapy: Systematic review and meta-analysis. Clin Oral Implants Res 2018; 29 Suppl 18:54-92. https://doi.org/10.1111/clr.13282.

95. Ryu Jl, Kim HY, Kwon YD. Is implant surgery a risk factor for osteonecrosis of the jaw in older adult patients with osteoporosis? A national cohort propensity score-matched study. Clin Oral Implants Res 2021;32:437-47. https://doi. org/10.1111/clr.13713.

96. Kwon TG, Lee CO, Park JW, et al. Osteonecrosis associated with dental implants in patients undergoing bisphosphonate treatment. Clin Oral Implants Res 2014;25:63240. https://doi.org/10.1111/clr.12088.

97. Jacobsen C, Metzler P, Rössle M, et al. Osteopathology induced by bisphosphonates and dental implants: clinical observations. Clin Oral Investig 2013;17:167-75. https: //doi.org/10.1007/s00784-012-0708-2.

98. Lazarovici TS, Yahalom R, Taicher S, et al. Bisphosphonaterelated osteonecrosis of the jaw associated with dental implants. J Oral Maxillofac Surg 2010;68:790-6. https:// doi.org/10.1016/j.joms.2009.09.017.

99. Kim YH, Lee HK, Song SI, et al. Drug holiday as a prognostic factor of medication-related osteonecrosis of the jaw. J Korean Assoc Oral Maxillofac Surg 2014;40:206-10. https://doi.org/10.5125/jkaoms.2014.40.5.206.

100. Hinchy NV, Jayaprakash V, Rossitto RA, et al. Osteonecrosis of the jaw - prevention and treatment strategies for oral health professionals. Oral Oncol 2013;49:878-86. https://doi.org/10.1016/j.oraloncology.2013.06.008.

101. Guarneri V, Miles D, Robert N, et al. Bevacizumab and osteonecrosis of the jaw: incidence and association with bisphosphonate therapy in three large prospective trials in advanced breast cancer. Breast Cancer Res Treat 2010; 122:181-8. https://doi.org/10.1007/s10549-010-0866-3.

102. Tsao C, Darby I, Ebeling PR, et al. Oral health risk factors for bisphosphonate-associated jaw osteonecrosis. J Oral Maxillofac Surg 2013;71:1360-6. https://doi.org/10.1016/ j.joms.2013.02.016.
103. Chalem M, Medina A, Sarmiento AK, et al. Therapeutic approach and management algorithms in medicationrelated osteonecrosis of the jaw (MONJ): recommendations of a multidisciplinary group of experts. Arch Osteoporos 2020;15:101. https://doi.org/10.1007/s11657-02000761-0.

104. Migliorati CA, Saunders D, Conlon MS, et al. Assessing the association between bisphosphonate exposure and delayed mucosal healing after tooth extraction. J Am Dent Assoc 2013;144:406-14. https://doi.org/10.14219/ jada.archive.2013.0134.

105. Fleisher KE, Welch G, Kottal S, et al. Predicting risk for bisphosphonate-related osteonecrosis of the jaws: CTX versus radiographic markers. Oral Surg Oral Med Oral Pathol Oral Radiol Endod 2010;110:509-16. https://doi. org/10.1016/j.tripleo.2010.04.023.

106. Taguchi A, Shiraki M, Tsukiyama M, et al. Impact of osteonecrosis of the jaw on osteoporosis treatment in Japan: results of a questionnaire-based survey by the Adequate Treatment of Osteoporosis (A-TOP) Research Group. Calcif Tissue Int 2015;97:542-50. https://doi.org/10.1007/ s00223-015-0045-y.

107. Carlson ER, Basile JD. The role of surgical resection in the management of bisphosphonate-related osteonecrosis of the jaws. J Oral Maxillofac Surg 2009;67:85-95. https:// doi.org/10.1016/j.joms.2009.01.006.

108. Ferlito S, Puzzo S, Palermo F, et al. Treatment of bisphosphonate-related osteonecrosis of the jaws: presentation of a protocol and an observational longitudinal study of an Italian series of cases. Br J Oral Maxillofac Surg 2012; 50:425-9. https://doi.org/10.1016/j.bjoms.2011.08.004.

109. Scoletta M, Arduino PG, Dalmasso P, et al. Treatment outcomes in patients with bisphosphonate-related osteonecrosis of the jaws: a prospective study. Oral Surg Oral Med Oral Pathol Oral Radiol Endod 2010;110:46-53. https: //doi.org/10.1016/j.tripleo.2010.02.020.

110. Kademani D, Koka S, Lacy MQ, et al. Primary surgical therapy for osteonecrosis of the jaw secondary to bisphosphonate therapy. Mayo Clin Proc 2006;81:1100-3. https: //doi.org/10.4065/81.8.1100.

111. Freiberger JJ, Padilla-Burgos R, McGraw T, et al. What is the role of hyperbaric oxygen in the management of bisphosphonate-related osteonecrosis of the jaw: a randomized controlled trial of hyperbaric oxygen as an adjunct to surgery and antibiotics. J Oral Maxillofac Surg 
2012;70:1573-83. https://doi.org/10.1016/j.joms.2012. 04.001.

112. Park JH, Kim JW, Kim SJ. Does the addition of bone morphogenetic protein 2 to platelet-rich fibrin improve healing after treatment for medication-related osteonecrosis of the jaw? J Oral Maxillofac Surg 2017;75:1176-84. https: //doi.org/10.1016/j.joms.2016.12.005.

113. Kim JW, Kim SJ, Kim MR. Leucocyte-rich and platelet-rich fibrin for the treatment of bisphosphonate-related osteonecrosis of the jaw: a prospective feasibility study. $\mathrm{Br}$ J Oral Maxillofac Surg 2014;52:854-9. https://doi.org/10. 1016/j.bjoms.2014.07.256.

114. Vescovi P, Merigo E, Meleti M, et al. Bisphosphonates-related osteonecrosis of the jaws: a concise review of the literature and a report of a single-centre experience with 151 patients. J Oral Pathol Med 2012;41:214-21. https:// doi.org/10.1111/j.1600-0714.2011.01091.x.

115. Song KE, Min YK, Lee JK, et al. A probable case of oral bisphosphonate-associated osteonecrosis of the jaw and recovery with parathyroid hormone treatment. Curr Ther Res Clin Exp 2008;69:356-62. https://doi.org/10.1016/ j.curtheres.2008.08.003.

116. Bashutski JD, Eber RM, Kinney JS, et al. Teriparatide and osseous regeneration in the oral cavity. N Engl J Med 2010; 363:2396-405. https://doi.org/10.1056/NEJMoa1005361.

117. Gerard DA, Carlson ER, Gotcher JE, et al. Early inhibitory effects of zoledronic acid in tooth extraction sockets in dogs are negated by recombinant human bone morphogenetic protein. J Oral Maxillofac Surg 2014;72:61-6. https://doi.org/10.1016/j.joms.2013.06.192.

118. Lee CY, David T, Nishime M. Use of platelet-rich plasma in the management of oral biphosphonate-associated osteonecrosis of the jaw: a report of 2 cases. J Oral Implantol 2007;33:371-82. https://doi.org/10.1563/15481336(2007)33[371:Uoppit]2.0.Co;2.

119. Fedele S, Porter SR, D'Aiuto F, et al. Nonexposed variant of bisphosphonate-associated osteonecrosis of the jaw: a case series. Am J Med 2010;123:1060-4. https://doi. org/10.1016/j.amjmed.2010.04.033.

120. Schiodt M, Reibel J, Oturai $P$, et al. Comparison of nonexposed and exposed bisphosphonate-induced osteonecrosis of the jaws: a retrospective analysis from the Copenhagen cohort and a proposal for an updated classification system. Oral Surg Oral Med Oral Pathol Oral Radiol 2014;117:204-13. https://doi.org/10.1016/j.00oo.2013.
10.010

121. Yarom N, Shapiro CL, Peterson DE, et al. Medication-related osteonecrosis of the jaw: MASCC/ISOO/ASCO Clinical Practice Guideline. J Clin Oncol 2019;37:2270-90. https: //doi.org/10.1200/jco.19.01186.

122. Hinson AM, Siegel ER, Stack BC, Jr. Temporal correlation between bisphosphonate termination and symptom resolution in osteonecrosis of the jaw: a pooled case report analysis. J Oral Maxillofac Surg 2015;73:53-62. https: //doi.org/10.1016/j.joms.2014.07.012.

123. Blick SK, Dhillon S, Keam SJ. Teriparatide: a review of its use in osteoporosis. Drugs 2008;68:2709-37. https://doi. org/10.2165/0003495-200868180-00012.

124. Rubin MR, Bilezikian JP. The anabolic effects of parathyroid hormone therapy. Clin Geriatr Med 2003;19:415-32. https://doi.org/10.1016/s0749-0690(02)00074-5.

125. McClung MR, San Martin J, Miller PD, et al. Opposite bone remodeling effects of teriparatide and alendronate in increasing bone mass. Arch Intern Med 2005;165:1762-8. https://doi.org/10.1001/archinte.165.15.1762.

126. Cheung A, Seeman E. Teriparatide therapy for alendronate-associated osteonecrosis of the jaw. $\mathrm{N}$ Engl J Med 2010;363:2473-4. https://doi.org/10.1056/NEJMc1002684.

127. Lee JJ, Cheng SJ, Jeng JH, et al. Successful treatment of advanced bisphosphonate-related osteonecrosis of the mandible with adjunctive teriparatide therapy. Head Neck 2011;33:1366-71. https://doi.org/10.1002/hed.21380.

128. Kim KM, Park W, Oh SY, et al. Distinctive role of 6-month teriparatide treatment on intractable bisphosphonaterelated osteonecrosis of the jaw. Osteoporos Int 2014;25: 1625-32. https://doi.org/10.1007/s00198-014-2622-8.

129. Jung J, Yoo HY, Kim GT, et al. Short-term teriparatide and recombinant human bone morphogenetic protein-2 for regenerative approach to medication-related osteonecrosis of the jaw: a preliminary study. J Bone Miner Res 2017;32:2445-52. https://doi.org/10.1002/jbmr.3237.

130. Sim IW, Borromeo GL, Tsao C, et al. Teriparatide promotes bone healing in medication-related osteonecrosis of the jaw: a placebo-controlled, randomized trial. J Clin Oncol 2020;38:2971-80. https://doi.org/10.1200/jco.19.02192.

131. Dhillon RS, Xie C, Tyler W, et al. PTH-enhanced structural allograft healing is associated with decreased angiopoietin-2-mediated arteriogenesis, mast cell accumulation, and fibrosis. J Bone Miner Res 2013;28:586-97. https:// doi.org/10.1002/jbmr.1765. 
132. Gilsenan A, Harris D, Reynolds M, et al. Long-term cancer surveillance: results from the Forteo Patient Registry Surveillance Study. Osteoporos Int 2021;32:645-51. https:// doi.org/10.1007/s00198-020-05718-0.
133. Gilsenan A, Midkiff K, Harris D, et al. Teriparatide did not increase adult osteosarcoma incidence in a 15-year US postmarketing surveillance study. J Bone Miner Res 2021; 36:244-51. https://doi.org/10.1002/jbmr.4188. 